\title{
Quantification of Human Perception Using the Motor Human-Computer Interface Hand Tracker
}

\author{
DOI: 10.17691/stm2019.11.1.16
}

Received December 18, 2018

V.A. Antonets, DSc, Professor, Department of Psychophysiology, Faculty of Social Sciences:;

Leading Researcher, Department of Radiophysical Methods in Medicine ${ }^{2}$

${ }^{1}$ National Research Lobachevsky State University of Nizhny Novgorod, 23 Prospekt Gagarina, Nizhny Novgorod, 603950, Russia;

${ }^{2}$ Federal Research Center Institute of Applied Physics, Russian Academy of Sciences, 46 Ulyanova St. Nizhny Novgorod, 603950, Russia

Here, we propose an all-instrumental objective method (hand tracking) for the real time quantification of perception of stimuli presented in various modalities.

The method is based on measuring the dynamic error of performance by a subject of motor control over a real or virtual (computer generated) stimulus with the help of a contactless manipulator. The method got its name from its previous analogue - the eye tracking; in both cases, the measurement of psychophysiological characteristics of the subject is carried out by monitoring the parameters of his/her motor activities.

The above principle has been implemented in the form of a hardware-software complex Hand tracker, which has been tested for the ability to perceive the "segment orientation angle" and "figure color against the background" virtual stimuli.

With the first stimulus, individual diagrams of perception accuracy were obtained in healthy subjects who were asked to guess the segment inclination angle. The results allowed us to identify the parameters of the neural model simulating the respective primary recognizer. With the second visual stimulus, we found that in patients with focal brain lesions, the thresholds of color differentiation were abnormally high and, unlike the normal ones, did not depend on the semantic content of the stimulus.

Since the Hand tracker provides for the simultaneous control over several (up to eight) independent parameters of audial and visual stimuli, the proposed method can be used in studying the intermodal connections and/or the collective behavior, when different team members control different parameters of the stimulus, trying to solve a common problem.

The article also addresses the prospect of implementing the hand tracking method in the form of special applications for smartphones with embedded movement sensors. Such a portable device could be used for epidemiological studies of perception (primary cognitive functions) to elucidate the age- and gender-related, regional, social and other stratification of populations.

Key words: virtual stimuli; perception; hand tracking; quantification of perception; cognitive diagnostics and rehabilitation; cognitive epidemiology.

\section{Introduction}

Knowledge of the quantitative characteristics of human perceptual systems is important for diagnosing primary cognitive disorders as well as for patient rehabilitation process. Specifically, we talk about controlling the technical, informational and exomotor interface components of simulators and systems that substitute the lost motor functions in patients.

The aim of the work was to substantiate, describe and demonstrate an all-instrumental objective method for quantifying the human perception and rationalize the prospects of its practical applications. The proposed method does not require any subject's verbalization on his/her subjective feeling aroused by the stimulus.

The method is based on measuring the dynamic error of performance of motor control over a real or virtual (computer generated) stimulus [1]. Here, the dependence of this error on a physical parameter of the external stimulus is used for characterizing the sensory analyzer. The method is termed hand tracking by analogy with the device proposed Yarbus [2] for the study of spatial attention, which is currently called the eye tracker. Both devices are designed to measure the psychophysical characteristics of a person by monitoring his/her motor acts.

The rationalization of the method was carried out using real stimuli of two types: a) "load weight", when voltage fluctuations of the shoulder biceps muscle were measured under loading with various weights; b) "tonal sound pitch" when frequency fluctuations of tonal sounds were compared for two cases: produced by a human voice and by an electronic voice generator controlled by a contactless manipulator.

The method is implemented in the form of a hardwaresoftware complex (HSC) Hand tracker, which allows one to quantify the perception of audial and visual stimuli in real time.

Corresponding author: Vladimir A. Antonets, e-mail: antonetsva@gmail.com 
The present article demonstrates the use of HSC for studying the perception of the virtual stimuli "segment orientation angle" and "color of a figure against a background". With the first stimulus, individual diagrams of perception accuracy were obtained in healthy subjects who were asked to guess the angle of segment inclination. The results allowed us to identify the parameters of the neural model simulating the respective primary recognizer. With the second visual stimulus, we found that in patients with focal brain lesions, the thresholds of color differentiation were abnormally high and, unlike the normal ones, did not depend on the semantic content of the stimulus.

Since the HSC Hand tracker allows for controlling several (up to eight) independent parameters of audial and visual stimuli, the proposed method can be used in studying the intermodal relations and/or the collective behavior. In the latter, different team members control different parameters of the stimulus, trying to solve a common problem: for example, to achieve a certain size and color of a circle. In both cases, the measurement procedure is also the training one.

A part of the Hand tracker potential can be implemented in the widely used smartphones equipped with movement sensors. Such a portable device can be used for epidemiological studies of perception (primary cognitive functions) in various age, gender, regional, social and other groups of the population.

\section{Instrumental study of perception: methods and problems}

To date, two methods for quantifying human perception of sensory stimuli are best known.

The first method was proposed at the beginning of the XVIII century by Bouguer [3], who studied the human perception of brightness of luminous objects for the purpose of improving marine navigation. He established the constancy of the ratio of the barely perceptible difference in brightness $\Delta R$ between two luminous objects to the background brightness $R$; this ratio is now called the relative differential threshold of perception. More than 100 years after that, Weber and then others showed that if the stimulus magnitude is far from the thresholds of perception and pain, the Bouguer rule holds for stimuli of other modalities $[4,5]$. This rule is usually expressed:

$$
\Delta R / R \cong k,
$$

where the value of $k$ depends on the modality of the stimulus; in the experiments of Bouguer, $k \cong 1 / 64$.

Assuming equality of the relative change in the magnitude of sensation and the relative change in the magnitude of the stimulus, which is subjectively evaluated by a person, i.e.,

$$
\Delta S / S=\Delta R / R,
$$

Fechner [6] concluded about a logarithmic relation between the magnitude of sensation $S$ and the magnitude of the stimulus $R$.

The second method, created by Stevens [7], is based on the assumption that the relative change in the sensation magnitude $\Delta S / S$ depends on the relative change in stimulus $\Delta R / R$ by a linear relationship, where the constant $\alpha$ depending on the modality of the stimulus can be either less or greater than a unit:

$$
\Delta S / S=\alpha \cdot \Delta R / R \text {. }
$$

From relation (3), for all values of $\alpha \neq 1$, i.e. other than a unit, there is a power relationship between the sensation $S$ and the stimulus $R$ :

$$
S / S_{0}=\left(R / R_{0}\right)^{\alpha}
$$

When $\alpha=1$, which corresponds to the Fechner hypothesis, there is a logarithmic relation between the sensation magnitude $S$ and that of the stimulus $R(3)$.

For the stimuli that are far from the thresholds of perception and pain, the formula (4) was confirmed experimentally by Stevens [7]. For many modalities of sensations, the values of $k$ and $\alpha$ have been measured and introduced into the reference manuals (for example, [8]).

A common shortcoming of both methods regarding the diagnosis and rehabilitation is that the subjects are aware of the emerging sensation and the verbal expression of the subjective assessment of its magnitude.

This technique is cumbersome, takes time and does not guarantee an objective verbal evaluation of the subjective feeling.

In [9], we demonstrated a fundamentally different all-instrumental method for quantifying the perception in real time; the proposed approach is free from subjectivism and verbalization. It is based on determining the dynamic error occurred in controlling a real or virtual (computer-generated) stimulus. In this case, the quantitative dependence of the dynamic error on a physical parameter of the external stimulus is used to characterize the sensory analyzer. This approach is based on a simple fact noted by Sechenov [10] that a human makes use of sensations as feedback for controlling his/her functions, e.g., movements.

\section{Description and rationalization of the using method}

The rationale for quantifying the perception was obtained from experiments with real stimuli: "load weight" [11, 12] and "tonal sound pitch" [13-15]. Thus, we measured micro-fluctuations of the shoulder biceps muscle force (with its antagonist - triceps muscle relaxed) needed to balance a load held on the distal part of the forearm bent at the elbow joint. We found that the average value of force fluctuations $f_{\text {fluct }}$ changed with changes in the mass $m$ of the load [11, 12]. In addition, these changes in the average fluctuation $\Delta f_{\text {fluct }}$ in 


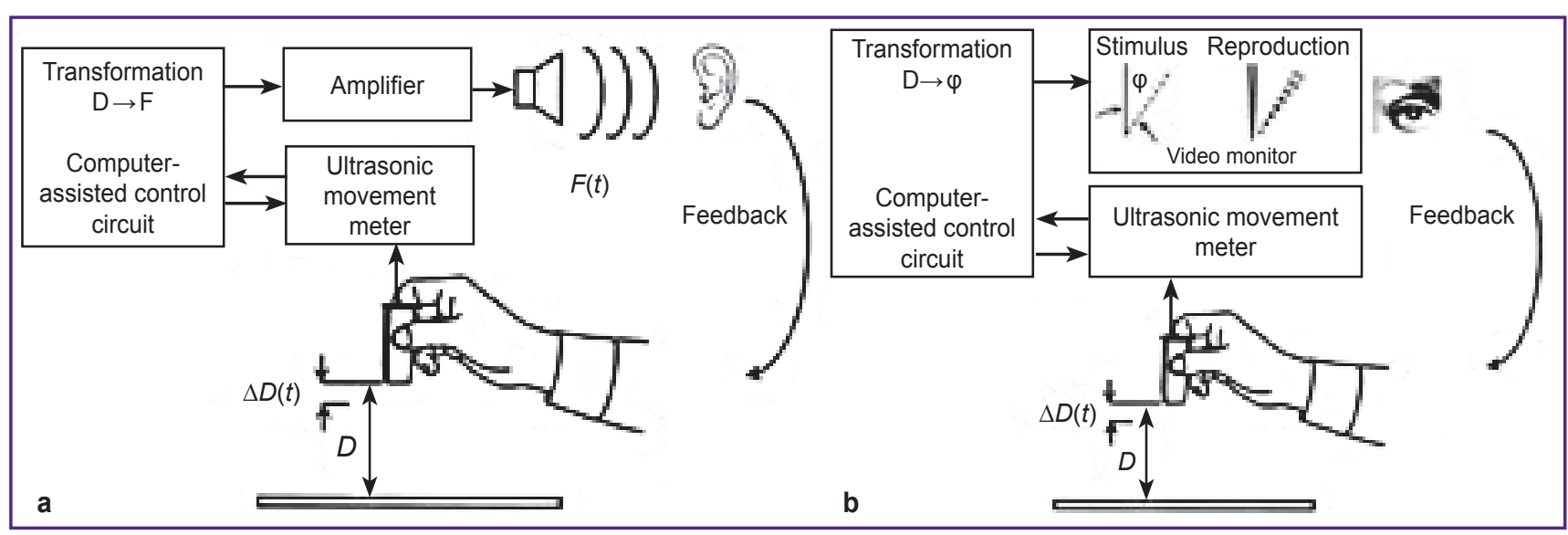

Figure 1. A contactless manipulator used to control the parameters of audial (a) and visual (b) stimuli (schematic representation) [1]

response to a change in the load mass $\Delta m$ obey relation (3) with an inaccuracy of $10 \%$ :

$$
\Delta f_{\text {fluct }} / f_{\text {fluct }}=\beta \cdot(\Delta m / m) \text {. }
$$

The coefficient $\beta$ had a value of $2.0-2.5$ in different subjects (10 people).

The relation (5) obtained by solely physical measurements and relation (3), obtained by a subjective psychophysical assessment, differ from each other only by the denoting symbols and, possibly, by the values of $\alpha$ and $\beta$. Therefore, the physical measurement of fluctuations (inaccuracies) of the muscle force is the objective measurement of perception in real time. Thus, the error of control is what creates the sensation and perception of gravity and, apparently, in this context, they can be simply identified with each other.

This interpretation of errors in controlling a stimulus was confirmed by studies on fluctuations of the frequency of a tonal sound generated by a subject's voice $[13,15]$ or a sound generator $[14,15]$. In the latter case, the frequency was controlled by changing the distance between a fixed coordinate plane and a contactless manipulator freely movable by the subject's hand (Figure $1(a)$ ).

This distance was measured using an ultrasonic locator and then transformed into a signal (the stimulus) that controlled the sound generator frequency. Since the subject's hand did not lean on any support, he/she was only able to change the sound frequency based solely on hearing, i.e., the same way as a natural voice production. Under both conditions (the voice and the generator), the measured frequency fluctuation $\Delta f$ was found proportional to the reproduced frequency $f$. This relation corroborates with formulas (1) and (3) and supports the idea that the relative error in controlling a stimulus (which necessarily implies the existence of feedback) precisely characterizes the quality of perception. In singing a tonal sound, the $\Delta f / \cong 0.15$. When a tonal sound is produced by a controlled generator, the $\Delta f / f$ depends on the coefficients $K(\mathrm{~Hz} / \mathrm{mm})$, which links the manipulator movement with a change in the frequency of the sound generator. With $K=0.17 f$, the value of $\Delta f / f$ from the generator becomes the same as that produced by voice.

Thus, there were no fundamental differences in the quality of voice and motor control of the sound pitch. This could be expected because the production of a tonal sound using a motor act is the usual work of musicians playing string and wind instruments or thereminvox, which can all be considered as controlled sound generators with feedback.

Later, we used the contactless manipulation technique to objectively measure the perception of not only sound but also visual stimuli of various types.

\section{The hardware-software complex Hand tracker}

The above rationale was used for the development of a manual tracking system $[16,17]$ that allowed us to measure in real time the quantitative parameters of perception of audial and visual stimuli.

This device makes it possible to form a virtually unlimited variety of visual stimuli and modes of their presentation. It implements the following types of visual stimuli: homothetic compression-extension (change in size) of flat figures; linear compression-extension of flat figures along any chosen axis; rotation of flat figures; movement of flat figures; change in color of the background figures; compression-extension of a straight line or segment of a curve; rotation of a line segment or curve segment; movement of a line segment or curve segment.

The proposed HSC Hand tracker also provides for formation of a wide variety of audial stimuli and modes of their presentation: a tonal or noise sound varying in its volume; a frequency-varying tonal sound; a sequence of paired sound pulses with a variable interpulse interval and a variable intensity, a binaural sequence of sound 
pulses with a variable repetition frequency and a variable interaural delay (laterometry); a binaural sequence of sound pulses with a variable repetition period and a content that can be home-made or quoted from external sources.

At the choice of the operator, the subject can control any stimuli using a contactless manipulator (Hand tracker itself), a joystick, arrows, assigned keyboard keys, a mouse, or a touchpad panel. In the HSC, the operator sets the factors for converting the magnitude of the control action (for example, moving the manipulator or the joystick) into the size of the change in the stimulus parameter. The background color and the outline of the figures (color, thickness) are also assigned by the operator. The basic stimulus can be a figure, a line or a sound from the library of stimuli or a quote from an external source.

The operator creates a test scenario by assigning a rule for changing the parameters of images and sounds. The rule can be specified by a formula or a discrete numerical series.

Each of the created scenarios, i.e. a set of parameters and modes of stimulus presentation, can be saved in the database as a configuration and called up for later experiments. The results of each experiment, as well as the subjects' personal data (in unlimited numbers), can also be stored in the database.

In addition to studying the perception of individual visual and audial stimuli, the HSC allows one to study intermodal interaction, since audial and visual stimuli can be presented simultaneously so to let the subject control both of them within the same manipulation. This set up provides for the option to compare errors in the perception of sounds and images, both individually and together.

The HSC Hand tracker provides for the possibility of simultaneous independent control of several (up to eight) parameters of audial and visual stimuli. Therefore, control over several stimulus parameters or several combinations of these parameters can be handled by two or more subjects; this would make it possible to compare the quality of their perceptions and study their collective behavior in controlling the stimuli. This means that the HSC Hand tracker, developed as a humanmachine perception interface, can also help creating a human-human perception interface and harmonizing the subjective perception images of interacting subjects.

The proposed method includes a number of classic psychological tests.

\section{Example of use: studying the perception of the "angle of segment orientation" visual stimulus}

The subject was tasked with using a manipulator (Figure 1 (b)) to control the orientation of a segment on the computer monitor so that the segment always stayed parallel to the model segment presented by the operator on the same screen. Then, deviations of the model segment were measured.

The operator presented three series of stimuli: by increasing from -90 to +90 angular degrees in increments of 22.5 angular degrees, then by decreasing and also by a random order. The subject maintained control over each angle for $5 \mathrm{~s}$. Every $0.1 \mathrm{~s}$, a digitized measurement of the segment orientation angle was made. Seventy people who considered themselves healthy took the tests once; 10 of them passed the test cycle 4 times, with one test per day for a week.

Figure 2 (a) shows the results of a typical test. Along the circumference, there are miniature graphs showing the time variation of the angular orientation of the test segment for each orientation angle of the model segment. In the center, there is a diagram (in the polar coordinates) showing the dependence of the root-mean-square dynamic deviation (the error) of the

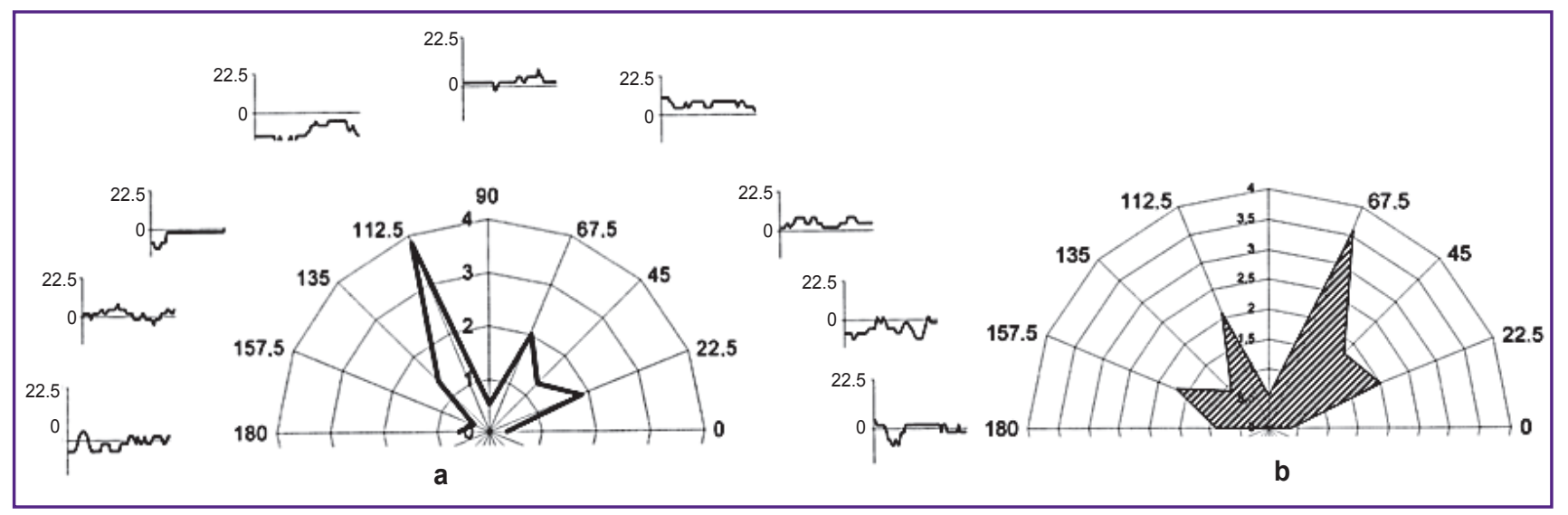

Figure 2. A typical result obtained in one subject (a) and the averaged orientation diagram for ten subjects (b)

Along the circumference, the angles of orientation of the model segment are shown; the radial coordinate indicates the mean square dynamic error of the angular orientation of the controlled segment with respect to the orientation of the model (in angular degrees) [1] 
controlled segment inclination angle on the model segment inclination angle. According to the results, individual orientation charts may vary on different days. Therefore, to assess the present state of the analyzer, the measurements must be made in real time. The diagram shows that with the least error was made when the subject worked with the vertical and horizontal segments. This result was true for

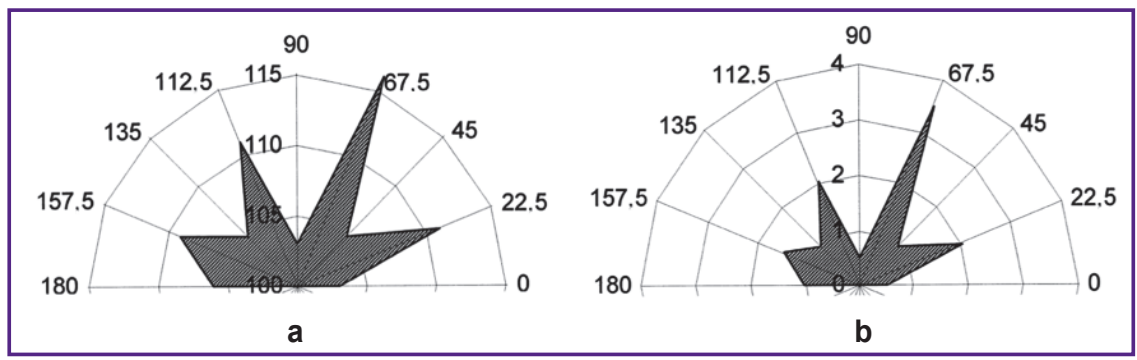

Figure 3. An individual orientation diagram obtained experimentally (a) and its theoretical analogue (b) based from a neuron-like model of the primary recognizer (receptive field) of segment orientation [1]

the orientation diagram averaged

for the 10 subjects who underwent four test cycles (Figure 2 (b)).

Measuring the individual orientation diagrams (the errors) opens up the possibility for evaluating the parameters of the neural network that functions as a primary recognizer. In Figure 3, the experimental and model diagrams are compared: those are diagrams of dynamic errors of control over the segment inclination angle.

Diagram in Figure 3 (b) is shown not in angular degrees but in arbitrary units, since there was no sufficient experimental data for the absolute calibration of the radial axis. However, we successfully used this data to identify the parameters of inter-neuronal connections and their excitation thresholds [18-20]. Interestingly, the discrepancy between the experimental and theoretical diagrams as a function of the magnitude of the receptive field (the number of neurons comprising the receptive field) has a minimum. In this model, the optimum performance of the primary recognizer is achieved for a network of approximately $10^{2}$ neurons, which work well with the number of neurons in the real recognition column [21].

\section{Example of use: studying the color discrimination in the "figure on the background" visual stimulus in patients with focal brain lesions}

To study the visual perception in patients with focal brain lesions, the HCS was used in the "campimetry" mode, i.e. for the measurement of color discrimination thresholds. As patients with brain lesions (and motor disorders) had difficulties in controlling the presented stimuli using a contactless manipulator, we could not measure the thresholds of color discrimination in dynamics. Therefore, we opted to measure the static thresholds of color distinction. In this setting, we presented colored shapes against a colored background; the patient was asked to control the shape color using buttons on the computer keyboard. We used three types of colored figures with different semantic content: a) geometric figures - a circle, a square, and a rectangle; b) images of animals and fruits; $c$ ) letters of the Russian alphabet.
The background color and the color of the stimuli were specified with the help of the HLS (hue, lightness, saturation) model [22]. The color tone $\mathrm{H}$ of the background was set by a scale from 0 to 240 arb. units and increments of 60 units with fixed saturation levels $S=220$ units and lightness $L=100$ units.

At first, the subject was presented with an image where the background color and the figure color were identical. By pressing the keyboard arrow, the subject increased the value of $\mathrm{H}$ by increments of $1 \mathrm{arb}$. unit until he/she detected the figure. In parallel, when the subject pressed the Enter key, the detection threshold of the color tone $\mathrm{H}$ was recorded by the system; if the figure was recognized incorrectly, the system recorded this result as an error. Either of the two results was reported by an arising icon. With a new keystroke, the subject was presented with a new image with a different color background value $\mathrm{H}$.

The primary data were collected from a group of neurological patients with confirmed diagnoses of "acute ischemic cerebrovascular accident", "acute cerebral hemorrhagic disorder", and "status after endoscopic removal of a left lateral ventricle cyst" (5 men, 4 women, 23-74 years old). The control group included conditionally healthy students from the Department of Psychophysiology of the National Research Lobachevsky State University of Nizhny Novgorod (5 males, 25 females, age 18-41 years).

The inclusion criteria for the study group were: a stable condition (satisfactory or moderate-severe), the absence of inflammatory diseases, the absence of severe somatic diseases in the off-remission stage at the time of the study, the proven ability of verbal contact, the understanding of relevant conversations, and the absence of severe motor deficit.

The study was conducted in accordance with the Helsinki Declaration (2013). An informed consent was obtained from each patient.

To study a relation between the semantic content of the stimulus and the thresholds of color discrimination, the Student's t-criterion was used to compare the data from the study and control groups (see the Table) presented with colored stimuli that were uniform in color tone but different in semantics. 
Color discrimination threshold values in the visual stimuli experiment

\begin{tabular}{|cccccc|}
\hline \multirow{2}{*}{$\begin{array}{c}\text { Semantics } \\
\text { of the stimulus }\end{array}$} & 0 & 60 & 120 & 180 & 240 \\
\hline GF & $7.33 \pm 3.56$ & $11.61 \pm 5.44$ & $8.03 \pm 2.70$ & $9.85 \pm 4.92$ & $9.45 \pm 4.25$ \\
\hline OI & $7.68 \pm 3.74$ & $10.14 \pm 5.06$ & $8.70 \pm 3.63$ & $8.02 \pm 4.53$ & 8.77 \\
\hline RAL & $6.97 \pm 2.58$ & $9.0 \pm 3.52$ & $7.48 \pm 3.29$ & $7.85 \pm 3.15$ & $8.58 \pm 3.99$ \\
\hline$P_{\text {GF/OI }}$ & 0.86 & 0.74 & 0.94 & 0.42 & 0.18 \\
\hline$P_{\text {GF/RAL }}$ & 1.0 & 0.13 & 0.56 & 0.34 & 0.61 \\
\hline$P_{\text {OIIRAL }}$ & 0.42 & 0.35 & 0.16 & 0.99 & 0.38 \\
\hline & & Control group & & \\
\hline GF & $2.10 \pm 0.87$ & $3.70 \pm 1.35$ & $4.23 \pm 1.38$ & $2.80 \pm 0.96$ & $3.33 \pm 1.11$ \\
\hline Ol & $2.37 \pm 0.84$ & $4.13 \pm 1.05$ & $4.73 \pm 1.25$ & $2.90 \pm 0.98$ & $3.40 \pm 1.21$ \\
\hline RAL & $1.93 \pm 0.87$ & $3.33 \pm 0.96$ & $3.90 \pm 1.17$ & $2.43 \pm 0.92$ & $2.70 \pm 1.01$ \\
\hline$P_{\text {GF/OI }}$ & 0.38 & 0.28 & 0.26 & 0.77 & 0.86 \\
\hline$P_{\text {GF/RAL }}$ & 0.58 & 0.34 & 0.45 & 0.27 & 0.10 \\
\hline P OI/RAL & 0.13 & 0.02 & 0.05 & 0.13 & 0.06 \\
\hline
\end{tabular}

H e r e: GF — geometric shapes; OI — object images; RAL — Russian alphabet letters.

According to the Student's criterion, there were statistically significant $(p<0.05)$ differences in the color discrimination thresholds between the study and control groups in respect to each type of color stimuli. At the same time, the color discrimination thresholds did not significantly differ between the subjects of the study group even if the semantics of the stimuli varied. In the control group, for color tone \#60 (green, [22]), there was a significant $(p<0.05)$ decrease in the color discrimination threshold for Russian letters images as compared to object images.

Thus, the proposed approach made it possible to reveal a qualitative abnormality of visual perception in patients with local brain lesions in two ways:

the color discrimination thresholds in patients are higher than normal for all types of stimuli that differ in the semantic content;

the semantics of the visual stimulus does not change the color discrimination threshold for any of the tested colors.

\section{Conclusion}

The examples of practical use of the all-instrumental quantification of perception, implemented in the form of the hardware-software complex Hand tracker, allow us to conclude that this method can be effectively used for laboratory and clinical studies on the perception of stimuli of various modalities. In this case, the measurement procedure itself is also a training one.

Unlike the traditional methods, the hand tracking has a much higher response rate and makes it possible to obtain the quantitative data on perception that have been unavailable previously.

The presence of several parallel channels for presenting the stimuli and controlling their parameters opens up the possibilities for objectively studying the perception of multimodal stimuli and the interaction between team members that collectively control the parameters of a virtual stimulus (for example, the size and color of an object). Thus, the hardwaresoftware complex Hand tracker can be interpreted as a human-human sensory interface, which provides the interacting subjects with the instrument to coordinate their subjective sensory images of the presented objects.

The explosive growth in the number of smartphone users provides the opportunity to develop a hand tracking method for epidemiological studies of perception (primary cognitive functions), taking into account regional, age, gender, social and other stratification of populations. The presence of embedded sensors in smartphones allows one to create special software applications $[17,23]$ that implement visual and audial perceptual tests. Moreover, some widely used applications and smartphone options can be modified into a perceptual test involuntary performed by the user (at his/her discretion). This development can produce surprising results, just as the creation of a network of meteorological stations made it possible to discover the existence of cyclones and anticyclones.

Acknowledgments. The author expresses his deep appreciation of S.A. Polevaya and M.M. Cirkova for their contribution to the research described in the article.

Research funding. This work was supported by grants from the Russian Foundation for Basic Research No.13-04-12063, No.05-08-33526-a, No.97-06-80286-a, No.00-06-80141-a and project No.0035-2014-0008 as part of the state-supported research program in the Institute of Applied Physics of the Russian Academy of Sciences.

Conflict of interest does not exist.

\section{References}

1. Antonets V.A., Polevaya S.A., Kazakov V.V. Hand tracking. Issledovanie pervichnykh kognitivnykh funktsiy cheloveka po ikh motornym proyavleniyam. $\mathrm{V}$ kn.: Sovremennaya eksperimental'naya psikhologiya. Tom 2 [Hand tracking. Study of the primary cognitive functions of a person by their motor manifestations. In: Modern experimental psychology. Vol. 2]. Pod red. Barabanshchikova V.A. Moscow: Institut psikhologii RAN; 2011; p. 39-55.

2. Yarbus A.L. Rol' dvizheniy glaz $v$ protsesse zreniya 
[The role of eye movements in the process of vision]. Moscow: Nauka; 1965.

3. Bouguer P. Sur la meilleure méthode pour observer l'altitude des étoiles en mer et Sur la meilleure méthode pour observer la variation de la boussole en mer. Paris; 1727.

4. Weber E.H. De pulsu, resorptione, auditu et tactu. Leipzig: Koehler; 1834.

5. Weber E.H. Der Tastsinn und das Gemeingefühl. In: Wagner R. (editor). Handwörterbuch der Phisiologie. Vol. III. Brunswick: Vieweg; 1846; p. 481-588.

6. Fechner G.T. Elemente der Psychophysik. Leipzig: Breitkopf und Härtel; 1860.

7. Stevens S.S. On the psychophysical law. Psychol Rev 1957; 64(3): 153-181, https://doi.org/10.1037/h0046162.

8. Lomov B.F. Spravochnik po inzhenernoy psikhologii [Lomov B.F. Handbook of engineering psychology]. Moscow: Mashinostroenie; 1982.

9. Antonets V.A., Kovaleva E.P., Zeveke A.V., et al. Novye cheloveko-mashinnye interfeysy. $\mathrm{V}$ kn.: Nelineynye volny. Sinkhronizatsiya $i$ struktury. Ch. 2 [New humanmachine interfaces. In: Nonlinear waves. Synchronization and structure. Part 2]. Pod red. Rabinovicha M.I., Sushchika M.M., Shalfeeva V.D. [Rabinovich M.I., Sushchik M.M., Shalfeev V.D. (editors)]. Nizhny Novgorod: Izdatel'stvo Nizhegorodskogo gosudarstvennogo universiteta; 1995; p. 87-98.

10. Sechenov I.M. Fiziologiya nervnykh tsentrov [Physiology of the nerve centers]. Saint Petersburg; 1891.

11. Antonets V.A., Kovaleva E.P. Evaluation of the static voltage control in the skeletal muscle by its micromovements. Biofizika 1996; 41(3): 711-717.

12. Antonets V.A., Kovaleva E.P. Statistical modeling of involuntary micro oscillations in a limb. Biofizika 1996; 41(3): 704-710.

13. Antonets V.A., Anishkina N.M., Kazakov V.V., Timanin E.M. Kolichestvennaya otsenka vospriyatiya chastoty zvukov slukhovym analizatorom. V kn.: XI sessiya Rossiyskogo akusticheskogo obshchestva [Quantification of the perception of the sound frequency by the auditory analyzer. In: XI session of the Russian Acoustic Society]. Moscow; 2001; p. 180-183.

14. Antonets V.A., Anishkina N.M., Gribkov A.L., Kazakov V.V., Timanin E.M. Kolichestvennaya otsenka vospriyatiya chastoty zvukov chelovekom $s$ ispol'zovaniem upravlyaemogo zvukovogo generatora. V kn.: XIII sessiya Rossiyskogo akusticheskogo obshchestva. Tom 3 [Quantifying human perception of the sound frequency using a controlled sound generator. In: XIII session of the Russian Acoustic Society. Vol. 3]. Moscow; 2003; p. 107-110.

15. Antonets V.A., Kazakov V.V., Anishkina N.M. Quantitative evaluation of tonal sound frequency perception by a man. Biophysics 2010; 55(1): 104-109, https://doi. org/10.1134/s0006350910010173.
16. Antonets V.A., Antonets M.A., Kazakov V.V., Il'in N.E., Kal'vaser I.B., Kryukov A.Yu., Pogodin V.Yu., Polevaya S.A. Programmno-apparatnyy kompleks "Handtracker" dlya izucheniya pervichnykh kognitivnykh funktsiy cheloveka po ikh motornym proyavleniyam. V kn.: Eksperimental'nyy metod $v$ strukture psikhologicheskogo znaniya [The softwarehardware complex "Handtracker" for the study of the primary human cognitive functions by their motor manifestations. In: Experimental method in the structure of psychological knowledge]. Moscow: Institut psikhologii RAN; 2012; p. 317-318.

17. Antonets V.A., Antonets M.A., Pogodin V.Yu., Kryukov A.Yu., Il'in N.E. Laboratornaya i mobil'naya versii metoda handtracking dlya issledovaniya pervichnykh kognitivnykh funktsiy cheloveka po ikh motornym proyavleniyam. V kn.: Protsedury i metody eksperimental'nopsikhologicheskikh issledovaniy [Laboratory and mobile versions of the hand tracking method for studying the primary cognitive functions by their motor manifestations In: Procedures and methods of experimental psychological research]. Pod red. Barabanshchikova V.A. [Barabanshchikov V.A. (editor)]. Moscow: Institut psikhologii RAN; 2016; p. 639-645.

18. Yakhno V.G, Nuidel I.V., Ivanov A.E. Model'nye neyronopodobnye sistemy. Primery dinamicheskikh protsessov. $\checkmark$ kn.: Nelineynye volny - 2004 [Neuron-like model systems. Examples of dynamic processes. In: Nonlinear waves - 2004]. Pod red. Gaponova-Grekhova A.V., Nekorkina V.I. [GaponovGrekhov A.V., Nekorkin V.I. (editors)]. Nizhny Novgorod: IPF RAN; 2004; p. 362-375.

19. Yakhno V.G., Polevaya S.A., Parin S.B. Bazovaya arkhitektura sistemy, opisyvayushchey neyrobiologicheskie mekhanizmy osoznaniya sensornykh kanalov. $\mathrm{V} k n$.: Kognitivnye issledovaniya. Tom 4 [The basic architecture of the system that describes the neurobiological mechanisms of awareness of sensory channels. In: Cognitive studies. Vol. 4]. Moscow: Institut psikhologii RAN; 2010; p. 273-301.

20. Antonets V.A., Nuidel I.V., Polevaya S.A. Adaptivnyy simulyator: komp'yuternaya tekhnologiya dlya rekonstruktsii orientatsionnykh moduley zritel'noy kory cheloveka. V kn.: Materialy XVI mezhdunarodnoy konferentsii po neyrokibernetike. Tom 2 [Adaptive simulator: computer technology for the reconstruction of the orientation modules of the human visual cortex. In: Materials of the XVI International conference on neurocybernetics. Vol. 2]. Rostov-on-Don; 2012; p. 142-145.

21. Buxhoeveden D.P., Casanova M.F. The minicolumn hypothesis in neuroscience. Brain 2002; 125(5): 935-951, https://doi.org/10.1093/brain/awf110.

22. Rusak L.V., Kalina V.A., Stasevich N.A. Komp'yuternaya grafika [Computer graphics]. Minsk; 2009.

23. URL: http://ma-tec.ru/handtracker.html. 